\title{
A case of Haemophilus parainfluenzae meningitis in an adult associated with acute myositis
}

\author{
A. TIMMIS \\ M.B., M.R.C.P.
}

\author{
E. NYHOLM \\ M.B.
}

\author{
R. J. DAWSON \\ M.B., M.R.C.P. \\ Hillingdon Hospital, Nr Uxbridge, Middlesex
}

\begin{abstract}
Summary
A rare case of Haemophilus parainfluenzae meningitis in an adult is reported. It was associated with acute myositis. This is thought to be the first report of such an association.

Introduction

Although several cases of Haemophilus parainfluenzae meningitis affecting children have been reported over the last 12 years, there are only 2 adult cases in the literature (Chow et al., 1974; Smith and Berger, 1974), both from the United States of America. A third case is now reported which is exceptional in that it was associated with acute myositis.
\end{abstract}

\section{Case report}

A 65-year-old woman presented with a 48-hr history of rigors and generalized muscle pain and weakness. She had had no serious illness in the past and had been on no drugs before admission. She had no history of upper respiratory tract infection or bronchitis.

On examination, her temperature was $38.5^{\circ} \mathrm{C}$; pulse was regular $90 / \mathrm{min}$; BP, $100 / 70 \mathrm{mmHg}$. The heart sounds were normal and the chest clear. There were no signs of endocarditis. Fundoscopy was normal and although initially there was no meningism, $12 \mathrm{hr}$ after admission she was complaining of headache and had developed a stiff neck in the absence of any focal neurological signs.

\section{Investigations}

$\mathrm{X}$-rays of chest, skull and sinuses were normal. CSF was turbid: microscopy showed large numbers of Gram-negative rods, 2 polymorphs and 4 red cells; protein, $3.24 \mathrm{~g} / 1$; glucose, $1.5 \mathrm{mmol} / \mathrm{l}$. Culture of CSF and blood grew $H$. parainfluenzae resistant to penicillin but sensitive to ampicillin and chlor- amphenicol. A throat swab failed to grow the organism and a urine culture was sterile. $\mathrm{Hb}$, $13.1 \mathrm{~g} / \mathrm{dl}$; WCC, $21.2 \times 10^{9} / 1 ; 94 \%$ neutrophils, $5 \%$ monocytes, $1 \%$ lymphocytes. Random blood sugar $3 \mathrm{mmol} / \mathrm{l}$; urea, $15 \mathrm{mmol} / 1$; electrolytes, normal. Liver function tests, normal; CPK, 740 i.u./1; amylase 59 Somogyi units.

She was treated in the first instance with i.v. ampicillin and chloramphenicol and the antibiotics were continued for 2 weeks, by which time recovery was complete. The temperature fell to normal within $36 \mathrm{hr}$ of admission, during which time her BP rose to $120 / 80 \mathrm{mmHg}$. Muscle pain remained severe for 8 days, requiring regular dihydrocodeine analgesia. Immunoglobulins 2 weeks after admission were found to be in the normal range and the relative lymphopenia noted on admission had recovered by this time. During the acute phase of her illness the Mantoux test (10 tuberculin units) was negative but the response became positive during convalescence.

\section{Comment}

Primary bacterial meningitis caused by $H$. parainfluenzae has been reported with increasing frequency in children since the first case in 1966 (Gullekson and Dumuff, 1966). However, so far as the present authors know, there have been only 2 adult cases reported (Chow et al., 1974; Smith and Berger, 1974).

In the present patient there appeared to be no predisposing cause for meningitis; the lymphopenia and failure to respond to tuberculin, both noted during the acute phase of the illness, normalized after the patient's recovery and were presumed secondary to overwhelming bacterial infection rather than representative of underlying immune deficiency. Likewise, her blood urea, which was elevated at the time of admission, fell into the normal range after recovery. 
Severe muscle pain with elevated CPK levels was thought to represent an associated acute myositis although muscle biopsy was not done. These symptoms had disappeared after 2 weeks, by which time the CPK level was in the normal range. This association of $H$. parainfluenzae meningitis and myositis has not previously been reported.

\section{Acknowledgments}

We wish to thank Dr G. C. Sutton, consultant cardiologist, Hillingdon Hospital, for allowing us to report this case; Dr D. Rimmer, consultant bacteriologist, Hillingdon Hospital, for help with the manuscript.

\section{References}

Chow, A.W., Bushkell, L.L., Yoshikawa, T.T. \& Guze, $\overrightarrow{\vec{F}}$ L.B. (1974) Haemophilus parainfluenzae epiglottitis with meningitis and bacteremia in an adult. American Journal of the Medical Sciences, 267, 365.

Gullekson, E.H. \& DUMUFF, M. (1966) Haemophilus parainfluenzae meningitis in a newborn. Journal of the $\mathbb{D}$ American Medical Association, 198, 1221.

SMITH, W.K. \& BeRger, H.W. (1974) Haemophilus para- के influenzae meningitis: a case in an adult. Mount Sinai Journal of Medicine. New York, 41, 543. 